\title{
Analysis of the Reasons for No Nobel Prize Winners in Literature in China before Mo Yan
}

\author{
Xuemei Li, Yinghong Zuo \\ Northeast Electric Power University, China
}

Keywords: Nobel Prize in Literature; language; rules; culture.

\begin{abstract}
China has 5,000 years of civilization and fruitful derivative literature. However, at the annual Nobel Prize in Literature Award, China always missed it until Mo Yan's work "Red Sorghum" broke the situation. There is no doubt about the deepness of Mo Yan's works is excellent. Before Mo Yan, is there anyone in the Chinese literary world who could stand shoulder to shoulder with him? Definitely no. Meanwhile, what is the reason why China did not get Nobel Prize in Literature before Mo Yan? A brief analysis on it is conducted in this paper. Although there has been only one Chinese writer, Mo Yan, who won the Nobel Prize in Literature, it does not mean that China does not have outstanding works. With the improvement of China's national strength, literature will be increasingly highly valued within our nation. Therefore, the acquisition of the Nobel Prize in Literature by Chinese writers will be just around the corner.
\end{abstract}

\section{Introduction}

The Nobel Prize was founded in 1900 and is based on the partial inheritance of the famous Swedish inventor and chemist Alfred Behreh Nobel. Nobel Prize consists of six major awards: Physics Prize, Chemistry Prize, Physiology or Medicine Prize, Economics Prize, Literature Prize, and Peace Prize. The Literary Prize is awarded to "those who have written in recent years or whose works' significance has been shown in recent years, and who have created the best works of ideals in literature." Generally speaking, in the first few days of October every year, before the Nobel Prize in Literature awards ceremony is held in Stockholm, Sweden, the annual Nobel Prize in Literature will be announced.

In recent days, prior to the promulgation of the Nobel Prize in Literature each year, China is always filled with a panic-stricken atmosphere. Although China has 5,000 years of civilization and its derivative works of literature are more fruitful, but on every eve of Nobel Prize in Literature Award, China is always with the emotion until 2012 when Mo Yan's work "Red Sorghum" broke that situation. The excellent deepness of Mo Yan's works is undeniable. Before that, is there no one in the Chinese literati go along with it? The answer is no. So what are the reasons why China has so far only one writer who won this award?

\section{Language}

\subsection{Language}

Literary works are based on text symbols as the carrier, which is the biggest difference compared to other art types. Writing is a tool to communicate, carry information and convey emotions, and language is the medium of words and things (information, emotion, etc.). In order to facilitate interpersonal communication, different regions form different languages. At the same time, the closer the cultural backgrounds of geographical locations among the regions are, the more similarity and commonality exist between languages. To put this phenomenon into the Nobel Prize in Literature: for the Nobel Prize awarding agencies, English works are more likely to be understood and their connotations and styles are more easily grasped than Chinese works. In response to this phenomenon, a simple statistical analysis was made on the use of the Nobel Prize Winners' Language as the 
following:

\begin{tabular}{|l|l|l|l|}
\hline \multicolumn{3}{|c|}{ analysis on the use of the Nobel Prize Winners Language from 1901 to 2017} \\
\hline language & number & language & number \\
\hline English & 28 & Arabic & 1 \\
\hline French & 14 & Bengalese & 1 \\
\hline Germany & 13 & Chinese & 1 \\
\hline Spanish & 11 & Czech & 1 \\
\hline Swedish & 7 & Finnish & 1 \\
\hline Italian & 6 & Hebrew & 1 \\
\hline Russian & 6 & Hungarian & 1 \\
\hline Polish & 4 & Yiddish & 1 \\
\hline Danish & 3 & Icelandic & 1 \\
\hline Norwegian & 3 & Occitan & 1 \\
\hline Greek & 2 & Portuguese & 1 \\
\hline Japanese & 3 & Serbian & 1 \\
\hline Turkish & 1 & & \\
\hline
\end{tabular}

This table shows that the largest proportion of literary awards winners are Germanic users, followed by the Latin family. In the analysis of the regions, we can see that the winners Europe, and accurately speaking, they are mainly concentrated in the Nordic and Western European countries sharing similar geographic and cultural backgrounds with Sweden. However, there are only a few countries in Asia, Africa and Australia that are far away from Sweden. However, this does not mean that there can be no winners in places such as Asia, Africa and Australia. Rather, if the writers in these regions want to receive awards or if they want to win the favor of the Nobel Prize awarding agencies, their works must be more insightful, connotative and fabulous. Therefore, works with similar language background are more easily to stand out.

\subsection{Translating}

When literary works enter into the world, the biggest obstacle is language. Therefore, a good translation is essential. Although most of the literary prize judges are familiar with four or five languages, only one judge, Professor Ma Yueran, knows Chinese well. The judges do not have the obligation to study Chinese and Chinese culture. Thus, they can only judge with the help of translations, so the translation is of great significance. However, the problem is that at the moment translators and translation versions of literary works are not lacking, but they still can't win awards. Therefore, what's the reason?

Firstly, it is the untranslatability. Language and culture are included. When Chinese is translated into English or Swedish, the Chinese phonetics, rhetoric, etc. are not translatable, because it may lose the beauty of Chinese itself. In the meantime, all ethnic groups have different cultures. When Chinese is translated into other languages, some cultural terms or connotations are also not translatable. Therefore, when Chinese works are translated, it is easy to lose their essence.

Secondly, the level of translation works is limited. There are indeed a large number of translators. However, there are too few excellent translators as Xu Yuanchong. Many translators have poor Chinese skills, thus they can not accurately understand Chinese works, and their translation skills are limited. As a result, translation works are terrible.

\subsection{The form of expression}

Because the cultural traditions and ideologies between China and the west are different, literary expressions are definitely different. Chinese stories focus on the plots, while western stories concentrate more on characters' mental activities. Chinese characters are comparatively simple in character and often show the good and the evil. However, the western pays more attention to multiple combinations and the complexity of characters and their development. In addition, Chinese works are inclined to reveal conflicts and social issues more directly. There is a simplistic, formulaic and graphical tendencies. However, the western works lay emphasis on the conflicts among people and 
reflects the social life through the fate of human beings. Therefore, Western readers or recommended judges do not necessarily understand or accept the form of expression in Chinese literature.

\section{Rules}

\subsection{Rules}

The Nobel Prize in Literature states that awards are given to literary pioneers and innovators, to less famous but certainly outstanding writer of achievement, to make him famed by receiving award; awarded to the big name, but also accomplished great writers; Nobel Prize in Literature is not granted to those who died. Especially the last rule has a more prominent influence on Chinese writers. There are the four major classical novels in ancient China, meanwhile, Mao Dun, Lao She, Shen Congwen and so on, these writers are remarkable in modern times. Unfortunately, they are too long ago, or suit and magnificent translation versions didn't come out until the authors died. So they missed Nobel again.

\subsection{Bias}

Although the Nobel Prize has always claimed that its rules will not be subject to political interferences and other factors. However, the Nobel Prize judges each have their own world outlook, outlook on life, values, and different tastes of literature. Therefore, it is impossible for the selection of literary awards to be completely objective. Although the Swiss Academy of Sciences has always claimed that: Nobel Prize winner's decision is not subject to any political interference. This is impossible. Literature is one of the ideologies that can not be separated from human society and is bound to be influenced by political factors. On political issues, the Permanent Secretary of the Swedish Royal Academy of Arts, Renensun, said in 1985: "Politics does not affect the judging process, but the atmosphere in the outside world really affects the judging process ... In the process of determining candidates, our political beliefs, or political prejudices, subconsciously work somewhere "(quoted from the 1986 New Observer Jin Jianfan" Rafting Nobel Prize for Literature ").

At the same time according to the Nobel's wills: regardless of the state, regardless of nationality, literary prize should be awarded to people who create the ideal works with the best tendencies. However, according to the area where many winners of the Nobel Prize in Literature are located, it is still mainly in Europe and the United States. Regional bias is inevitable.

\section{Culture}

\subsection{Philosophy}

Philosophy has a vital impact on literature, and great writers in the history are mostly philosophers, such as Kant, Hugo, Tagore and so on. In the same period, there is contention of a hundred schools of thought in ancient China and the period of Neo-Confucianism in Song and Ming Dynasties is also the period when Chinese literature prospers. Literature is the manifestation of philosophy, in the meantime, philosophy is the theoretical foundation of literature, and ultimately level ofliterature is highly dependent on the height of philosophical thinking.

\subsection{Spiritual Connotation}

As the economic grows rapidly in contemporary China, the fast-food culture popularizes in literature. A batch of contemporary writers have catered to the mass public's need and exiled themselves for the sake of gaining commercial interests. At the same time, contemporary writers abandoned the traditional Chinese culture and did not root deep traditional soil, which also made them lack spiritual connotation and lost the most valued idealism of the Nobel Prize.

\section{Conclusion}

Although so far, only one Chinese writer, Mo Yan, won the Nobel Prize in Literature, but this does 
not mean that China does not have outstanding works. With the improvement of China's national strength and the gradual emphasis on literature by the country and its citizens, the future of Chinese writers' winning Nobel Prizes can be done right by the day.

\section{References}

[1] Professor Ma, Yueran. Why Is There no Winner in China[N/OL]? Press Center Auditorium Speech, Beijing, 2008.

[2] President Rabbit. Why Chinese Writers Delay in Absence of the Nobel Prize in Literature[N/OL]. Phoenix Culture Complex, 2012:10.

[3] Tao, Chaxin. Noble Prize in Literature and the Hope of Chinese Writers[N]. Lishui Teachers College, Lishui,1987, No.3.

[4] Zhang, Xiyu. Where did We Miss the Nobel Prize in Literature to a Kawabata Kang as an Example[J]? Art Forum Shanghai Lixin College of Accounting Foreign Languages Institute, Shanghai, 2009:200-233. 